\title{
PRINCIPLES OF MOTOR ORGANIZATION OF THE MONKEY CERVICAL SPINAL CORD ${ }^{1}$
}

\author{
A. B. JENNY2 AND J. INUKAI
}

Department of Neurology and Neurological Surgery, Washington University School of Medicine, St. Louis, Missouri 63110

Received July 12, 1982; Revised October 25, 1982; Accepted November 5, 1982

\begin{abstract}
The organization of spinal cord motor columns innervating 18 selected macaque forelimb muscles was studied with the technique of retrograde transport of horseradish peroxidase. The reliability of the method was evaluated in the cat hindlimb.

Motor columns innervating forearm muscles with similar actions on the hand appear to overlap in the anterior horn. Extensor moloneurons are generally positioned ventral and/or lateral to flexor motoneurons. Motoneurons controlling hand movement are located primarily in segments C8 and T1.
\end{abstract}

Motoneurons that innervate individual muscles are arranged in rostrocaudal columns in the anterior horn of the spinal cord. The segmental localization of motor columns innervating primate forelimb muscles was originally described by Sherrington (1898) in studies involving stimulation of individual ventral nerve roots. Although the somatotopic organization of motor columns in the anterior horn has been reported for the cat lumbosacral cord (Romanes, 1951; Burke et al., 1977; Sato et al., 1978), the only topographical data available for the monkey cervical cord relate to the distribution of motoneurons that contribute to individual ventral roots (Sprague, 1948) and major peripheral nerves (Reed, 1940).

In the present study we sought to determine both the segmental and topographical organization of individual motor columns involved in controlling hand movement in the monkey. The retrograde transport of horseradish peroxidase (HRP) from selected muscles to motoneurons was used (Burke et al., 1977; Sato et al., 1978; Richmond et al., 1978; Matusda et al., 1978; Landmesser, 1978).

\section{Materials and Methods}

The studies were carried out in 10 Macaca mulatta and $4 M$. fascicularis monkeys of both sexes (2.9 to 4.2 $\mathrm{kg})$. The reliability of the method was first evaluated in the cat.

Injection of muscles with HRP. Under ketamine and

${ }^{1}$ This work was aided by United States Public Health Service Grants NS 05580, NS 05656, NS 04513, and NS 00470. We are indebted to Dr. W. M. Cowan for guidance and support during this work and to Dr. S. Goldring, Dr. E. G. Jones, Dr. W. Landau, and Dr. T. A. Woolsey for help in the preparation of this manuscript.

${ }^{2}$ To whom correspondence should be addressed. barbiturate anesthesia the desired muscle was cxposed and, with the use of an operating microscope, was carefully dissected from surrounding muscles. Care was taken to preserve the neurovascular pedicle. Muscles were identified by anatomic position, tendinous insertion, and when necessary, by electrical stimulation of the muscle (Hartman and Straus, 1933). The muscles were injected from a 27 gauge needle over 15 min at multiple sites with a saline solution of HRP (25,000 units/ml, Sigma HRP type VI, St. Louis, MO). Sufficient HRP was injected to render each muscle a dark brown color. To prevent the spread of HRP to adjacent muscles, Silastic and cotton barriers were positioned between the muscle to be injected and the surrounding muscle groups. The tissues surrounding the injected muscle were irrigated frequently with normal saline after the injection. By $3 \mathrm{hr}$, the injected muscle had returned to a more normal appearance and visible HRP leakage had stopped. Less frequent irrigation was continued for approximately $12 \mathrm{hr}$ postinjection and the Silastic and cotton barriers remained in place for the duration of the experiment.

Study of the spinal cord. After $48 \mathrm{hr}$ under anesthesia, each animal was heparinized and perfused through the heart with $300 \mathrm{ml}$ of normal saline and $5000 \mathrm{ml}$ of freshly prepared $0.5 \%$ paraformaldehyde and $2.5 \%$ glutaraldehyde in $0.1 \mathrm{M}$ phosphate buffer at $\mathrm{pH}$ 7.4. The brachial plexus was dissected to determine the major roots of origin. The cervical cord was removed and the segmental levels were marked on the ventral surface of the cord with shallow oblique slits which crossed the midline between adjacent segments. The border between segments was estimated visually as lying between the most caudal and rostral rootlets of adjacent segments. After 3 days in phosphate-buffered $30 \%$ sucrose, the cervical cord 
from $\mathrm{C} 4$ to $\mathrm{T} 3$ was frozen and sectioned serially in either transverse or horizontal planes at $50 \mu \mathrm{m}$. Serial sections were reacted according to Mesulam's (1976) benzidine dihydrochloride technique to demonstrate HRP enzymatic activity, mounted, and counterstained with neutral red.

Data analysis. The entire cervical cord from $\mathrm{C} 4$ to T3 was examined serially for motoneurons containing blueblack intracytoplasmic granules (Fig. 1). Labeled neurons were outlined in the plane of the nucleolus with a camera lucida at a final magnification of $\times 1000$ and their segmental level was charted. Sections with multiple labeled neurons were traced at $\times 170$ magnification and tracings of adjacent sections were compared to identify parts of individual neurons found in adjacent sections.

The size of each motoneuron was expressed as an average of orthogonal diameters which were measured on the camera lucida drawings. Proximal dendrites were drawn to conform to the general shape of the motoneuron; the method was similar to that of Burke et al. (1977).

The topographical position of a labeled motor group at a particular level of the spinal cord was established by entering the positions of labeled motoneurons in five consecutive $50-\mu \mathrm{m}$ sections on a single representative camera lucida drawing of the anterior horn. Drawings of each segment were made at the mid-upper half (rostral) and mid-lower half (caudal) of the segment. At the rostral C7 and caudal C8 levels of the cord, the motor groups were entered on a single tracing and composite drawings were made.
Dorsal rhizotomy and peripheral nerve analysis. In two $M$. fascicularis, unilateral rhizotomies of dorsal root ganglia C3 through T2 were performed in order to deafferent motor nerves and assess numbers and sizes of motor axons. After 45 days of uncomplicated survival the extensor digitorum communis muscles were injected bilaterally with HRP and the animals were studied as outlined above.

The axonal size distributions in the motor nerves to two deafferented extensor digitorum communis muscles and three normally innervated medial heads of the gastrocnemius muscle were studied. The limbs were postfixed in $10 \%$ formalin for 3 days and the motor nerves were dissected. At $20 \mathrm{~mm}$ from the extensor digitorum communis muscle, the motor nerve could no longer be separated readily from the remainder of the radial nerve; sections of nerve were obtained, postfixed in osmium tetroxide, embedded in Epon, and sectioned at approximately $1 \mu \mathrm{m}$ thickness. Sections of the nerve to the medial head of the gastrocnemius muscle were obtained about $5 \mathrm{~cm}$ from the muscle and similarly studied.

\section{Results}

\section{Evaluation of method}

Although injection of muscles with HRP has been used by others to demonstrate motoneuron organization, the initial effort of the study was to verify the quantitative reproducibility of the method. Major problems were the prevention of HRP uptake by adjacent muscles and their

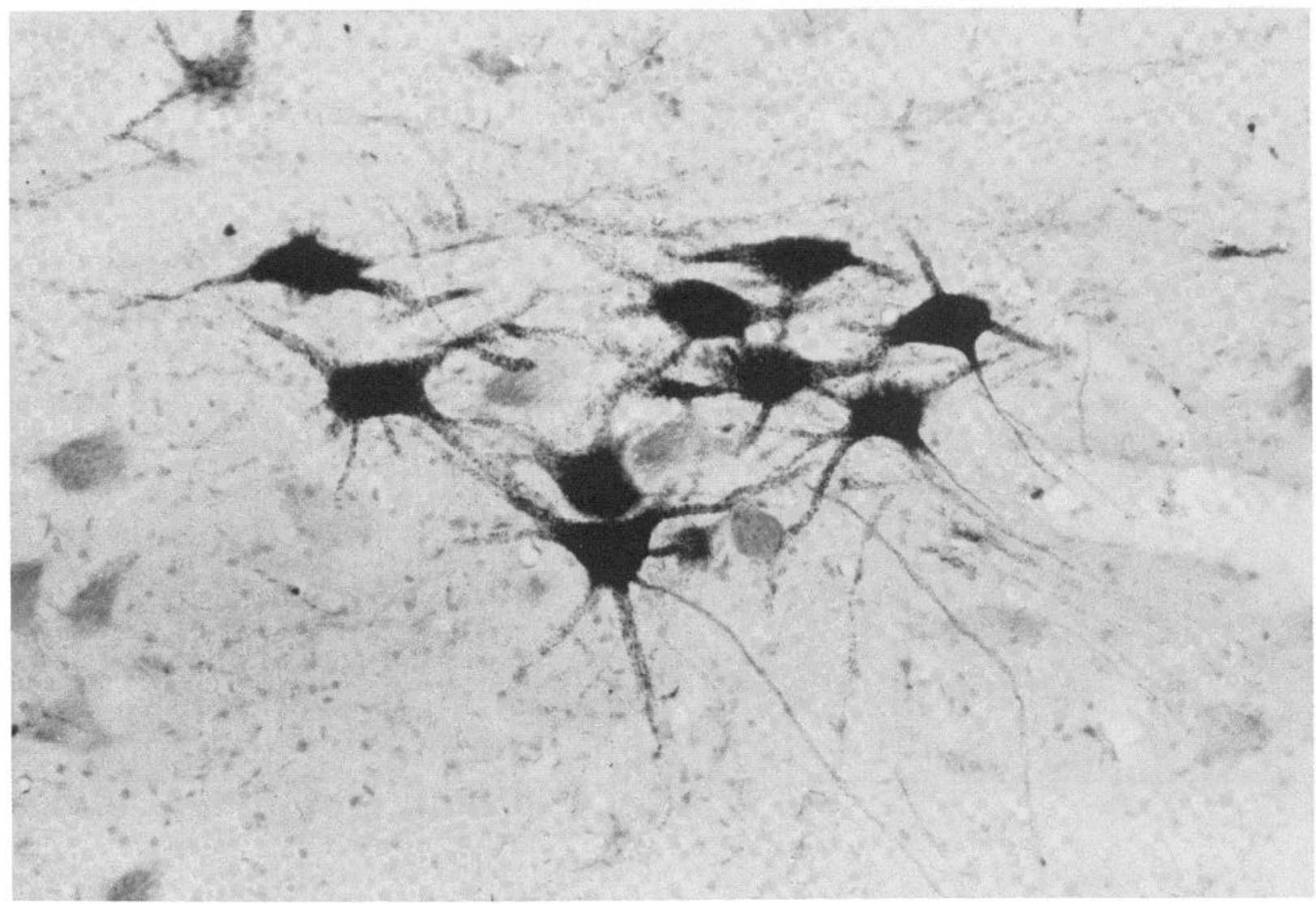

Figure 1. Motoneurons of the flexor digitorum profoundus (radial head) motor group labeled with blue-black intracytoplasmic granules. Magnification $\times 100$. 
motor nerves, selection of an appropriate survival period to maximize motoneuron labeling, and assessment of the number of labeled neurons in the motoneuron pool.

Motoneuron labeling. A survival period of $48 \mathrm{hr}$ was chosen after control studies showed that, regardless of length of nerve, motoneurons were labeled $48 \mathrm{hr}$ after muscles were injected with HRP. It was also found that $48 \mathrm{hr}$ were needed to assure good labeling of both large and small motoneurons in the monkey cord after injections into forelimb muscles.

The disappearance of HRP from labeled cells was also considered. Control experiments in the cat forelimb which compared the degree of motoneuron labeling after 1-, 2-, and 3-day survivals showed less HRP labeling in the cord after the longer survival periods. In the monkey a 2-day survival period was chosen since it seemed to represent the best balance between sufficient transport time and minimal catabolism time.

Controlling HRP spread to other muscles. The validity of the study depended on ensuring that the labeled neurons found in the anterior horn projected to an individual muscle. The technique which appeared to prevent adjacent muscles from taking up HRP and their nerves from transporting it retrogradely was the positioning of soft Silastic and cotton barriers around the injected muscle and the frequent irrigation of the surrounding space with normal saline during the critical period of leakage. In control experiments, in which the motor nerve to the muscle was ligated before HRP was injected, no HRP-labeled motoneurons were found in the anterior horn if the barriers and irrigation were used.

Quantitative analysis of method. Although each muscle was heavily injected with HRP, the diffusion of HRP throughout the muscle was uneven and some sectors of the muscle probably contained heavier deposits of HRP than others. 'The muscle fibers of individual motor units are randomly distributed throughout a sector of muscle (reviewed by Buchthal and Schmalbruch, 1980); this distribution would tend to expose some of the axon terminals of most motor units to the more heavily deposited areas of HRP.

Quantitative labeling of a motor group was assessed in two ways. We first compared the size of the extensor digitorum communis motor group in the same animal and across animals (Table $\mathrm{I}$ ). The average number of motoneurons was 294 in five monkeys and 296 in three cats; the standard deviation was less than $10 \%$ in both

TABLE I

Segmental distribution of HRP-labeled motoneurons (MN) and dorsal root ganglion neurons (DRG)

\begin{tabular}{lccccccrcc}
\hline Extensor Digitorum Communis & C5 & C6 & C7 & C8 & T1 & T2 & $\begin{array}{c}\text { Total } \\
\text { Motoneurons }\end{array}$ \\
\hline Cat & $78-9 \mathrm{R}$ & $\mathrm{MN}$ & 0 & 0 & 8 & 250 & 50 & 0 & 308 \\
Cat & $79-7 \mathrm{~L}$ & $\mathrm{MN}$ & 0 & 0 & 0 & 147 & 130 & 0 & 277 \\
Cat & $79-7 \mathrm{R}$ & $\mathrm{MN}$ & 0 & 0 & 13 & 291 & 8 & 0 & 312 \\
Monkey & $78-3 \mathrm{R}$ & $\mathrm{MN}$ & 0 & 0 & 6 & 179 & 88 & 0 & 273 \\
Monkey & $78-4 \mathrm{R}$ & $\mathrm{MN}$ & 0 & 0 & 1 & 180 & 157 & 0 & 338 \\
Monkey & $79-3 \mathrm{R}$ & $\mathrm{MN}$ & 0 & 0 & 2 & 136 & 137 & 0 & 275 \\
& & $\mathrm{IRG}$ & 0 & 8 & 53 & 110 & 24 & 0 & \\
Monkey & $79-3 \mathrm{~L}$ & $\mathrm{MN}$ & 0 & 0 & 3 & 152 & 139 & 0 & 294 \\
Monkey & $78-14 \mathrm{~L}$ & $\mathrm{MN}$ & 0 & 0 & 9 & 165 & 118 & 0 & 292 \\
& & $\mathrm{DRG}$ & & 14 & 34 & 123 & 19 & & \\
\hline
\end{tabular}

TABLE II

Motoneuron vs, axon counts (medial gastrocnemius, cat)

\begin{tabular}{lccccc}
\hline \multicolumn{1}{c}{ Source } & $\begin{array}{c}\text { Motoneu- } \\
\text { rons }\end{array}$ & $\begin{array}{c}\text { Myeli- } \\
\text { nated } \\
\text { Efferent } \\
\text { Axons }\end{array}$ & $\begin{array}{c}\text { Dorsal } \\
\text { Root Gan- } \\
\text { glion Cells. }\end{array}$ & $\begin{array}{c}\text { Myeli- } \\
\text { nated } \\
\text { Afferent } \\
\text { Axons }\end{array}$ & $\begin{array}{c}\text { Tulal My- } \\
\text { elinated } \\
\text { Axons }\end{array}$ \\
\hline F79-4(R) & 500 & & & & 810 \\
F79-6(R) & 573 & & 225 & 760 \\
F79-6(L) & 491 & & & & 726 \\
$\begin{array}{l}\text { Eccles \& Sherring- } \\
\text { ton (1930) }\end{array}$ & & $409(7)$ & $249(2)$ & \\
Boyd \& Davy (1968) & & $466(2)$ & $287(2)$ & $756(4)$ \\
\hline
\end{tabular}

species. When left and right motor groups in the same animal were compared, the numbers of motoneurons were within $6 \%$ of each other. This reproducibility suggested that a consistent and maximum number of neurons was being labeled.

Comparison of motoneuron and motor axon counts. The other quantitative assessment of the method compared the number of HRP-labeled motoneurons innervating the medial gastrocnemius muscle with the number of motor axons in the motor nerve. Eccles and Sherrington (1930) had observed that axons branch in motor nerves before they enter muscle and they had suggested that the nerve to the medial gastrocnemius muscle was better suited for determining nerve fiber counts since its motor nerve was longer than other motor nerves and more accurate counts could be made farther from the muscle. In the present study a reproducible number of medial gastrocnemius motoneurons $(505 \pm 3 \%$ in three cats) were labeled with HRP (Table II).

The numbers of medial gastrocnemius motor axons which have been counted by others in the cat after dorsal rhizotomy vary. Eccles and Sherrington (1930) observed a range of 307 to 459 motor axons and Boyd and Davey (1968) reported 466. Unfortunately, removal of the dorsal root ganglion can damage ventral root axons and yield underestimates of motor innervation. The counts by Boyd and Davey (1968) (466) are within $10 \%$ of the mean observed in this study (Table II).

The number of motor axons was also estimated by subtracting the number of myelinated sensory axons from the total number of myelinated axons. Reported sensory innervation averages 268 axons in the cat (Eccles and Sherrington, 1930; Boyd and Davey, 1968) and the total myelinated innervation counted in the present study averaged 765 axons. The combined data also suggest that about 500 motor axons innervate the medial head of the gastrocnemius muscle (Table II).

In summary, control studies confirmed the value of HRP muscle injection to study motoneuron organization. Contamination of adjacent muscles was prevented and the bulk of the motor group innervating a muscle appeared to be labeled with HRP.

\section{Organization of motoneurons innervating the extensor digitorum communis}

The organization of the motoneurons of the extensor digitorum communis was studied in more detail than that of motoneurons related to other muscles. Cervical segments of the spinal cords were sectioned in either trans- 
verse or horizontal planes in order to understand better the three-dimensional organization of the motor group.

The bulk of the motoneurons were grouped into a longitudinal column which extended over the $\mathrm{C} 8$ and $\mathrm{T} 1$ segments (Fig. 2). At the rostral and caudal ends of the column, decreasing numbers of motoneurons were observed and a few of the most rostral cells extended into the caudal portion of $\mathrm{C} 7$. Throughout the motoneuron column the neurons tended to cluster. Unlabeled motoneurons were observed among the clusters of labeled motoneurons.

The motor pool numbered about 300 . Both large and small neurons were labeled and no special distribution was observed within the motor group. Axons, when labeled with HRP, were traced to their exit from the cord; this usually occurred within $250 \mu \mathrm{m}$ of the rostrocaudal position of the cell somata. No recurrent axon collaterals were observed but they might not have been labeled. In one deafferented animal, 188 motoneurons were labeled with HRP and 254 residual myelinated axons were observed in the motor nerve. This difference might have resulted from inadequate labeling of injured motor axons, but it could indicate that the distal axons branched before they entered the muscle.

A bimodal size distribution of labeled motoneurons was observed in both the cat and the monkey in the horizontal plane of section (Fig. 3). Most labeled neurons were either between 20 and $30 \mu \mathrm{m}$ or 40 and $50 \mu \mathrm{m}$ in diameter. The number of small neurons (under $32 \mu \mathrm{m}$ ), however, was considerably less in the macaque and the ability to label the entire complement of small motoneurons varied. In one monkey, 33 small neurons were la-

\section{EXTENSOR DIGITORUM COMMUNIS}
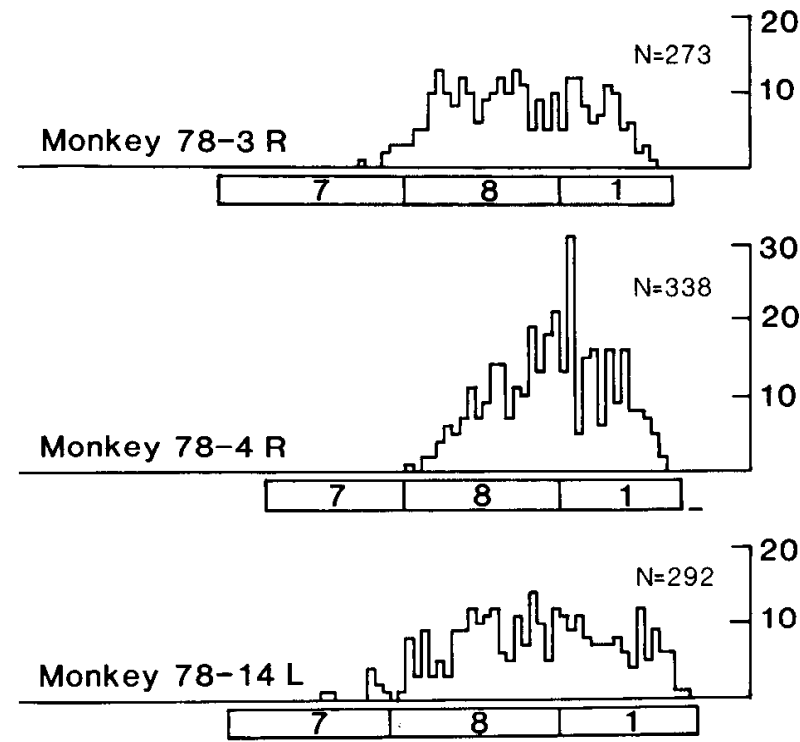

Figure 2. Segmental distribution of motoneurons innervating the extensor digitorum communis expressed as the number of labeled motoneurons per $250-\mu \mathrm{m}$ rostrocaudal distance. Segmental levels are charted underneath. $N$ equals total number of motoneurons.
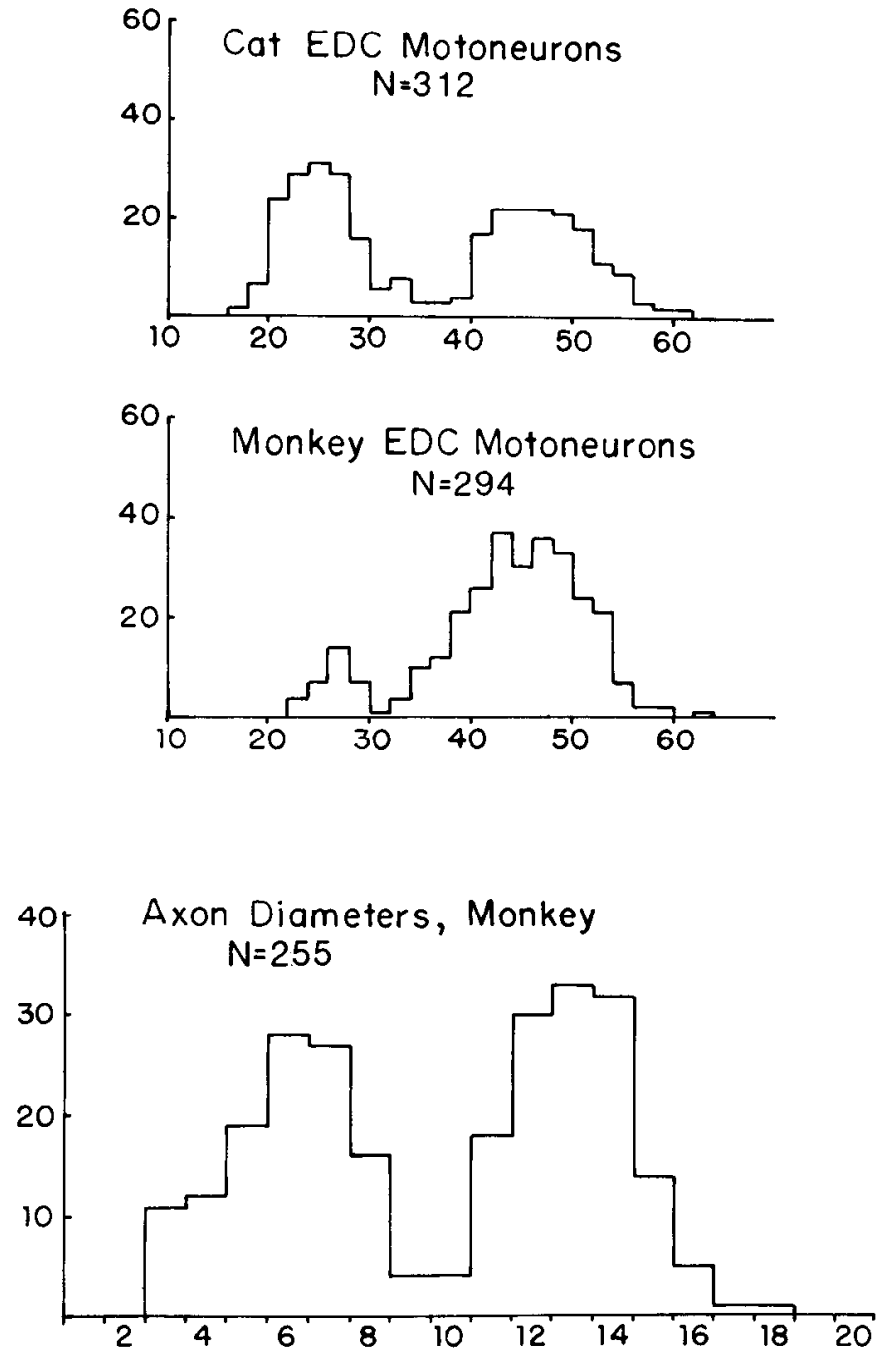

Figure 3. Diameters of motoneurons and motor axons innervating the extensor digitorum communis. Spinal cords were sectioned in the horizontal plane. Diameters of motoneurons are entered at $2-\mu \mathrm{m}$ intervals; no correction for shrinkage is made. $N$ equals total number of motoneurons or axons (cat 799L; monkey 78-3R). Axon diameters are total fiber diameter and are made approximately $10 \mathrm{~mm}$ distant from the muscle. Total number of axons, 255; axons, 3 to $9 \mu \mathrm{m}, 117,46 \%$. Axons 10 to $18 \mu \mathrm{m}, 138,54 \%$.

beled on one side and only 17 were labeled on the other. Although all neurons in the motor pool may not have been labeled, the segmental and topographical data should still be representative of the motor group since the control studies indicated most of the motoneurons in the motor group were labeled by the technique.

The sensory innervation was compared to the motor innervation in two of the muscles studied (Table I). Although most labeled sensory neurons were found in the dorsal root ganglia associated with the labeled motor group at C8 and T1, some labeled cells were also found in the more rostral ganglia of $\mathrm{C} 7$ and C6 (Eccles et al., 1968). Both small (18 to $20 \mu \mathrm{m}$ diameter) and large ganglion cells were labeled with HRP and no particular localization within the serially sectioned ganglia was apparent. 
Segmental and topographical organization of forelimb motoneurons

Representative muscles of the macaque arm, forearm, and hand were injected with HRP and the motoneuron columns were studied in the transverse plane. Whenever possible, antagonistic muscles were studied on opposite sides of the same animal in order to contrast topographical organization.

Arm muscles. The biceps and triceps were the only muscles studied in the arm (Figs. 4 and 5). The separation of these muscles from adjacent muscles was not clear in

\section{ARM MUSCLES}
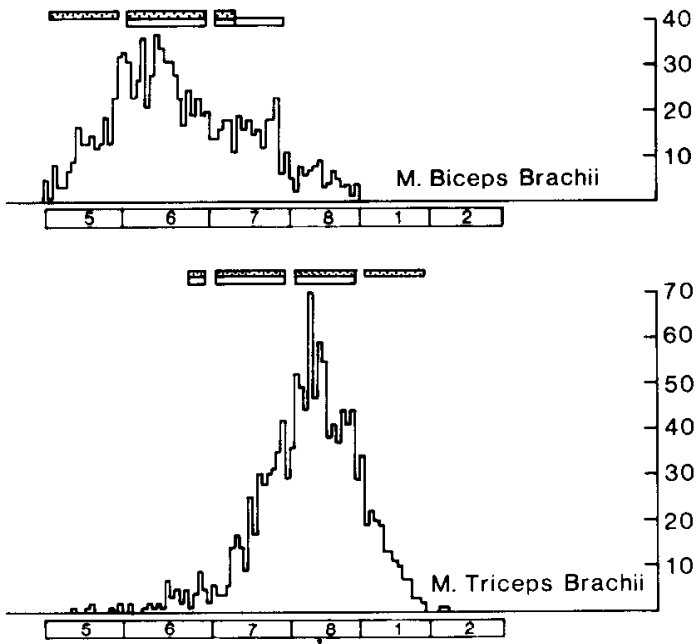

FOREARM MUSCLES (Wrist)
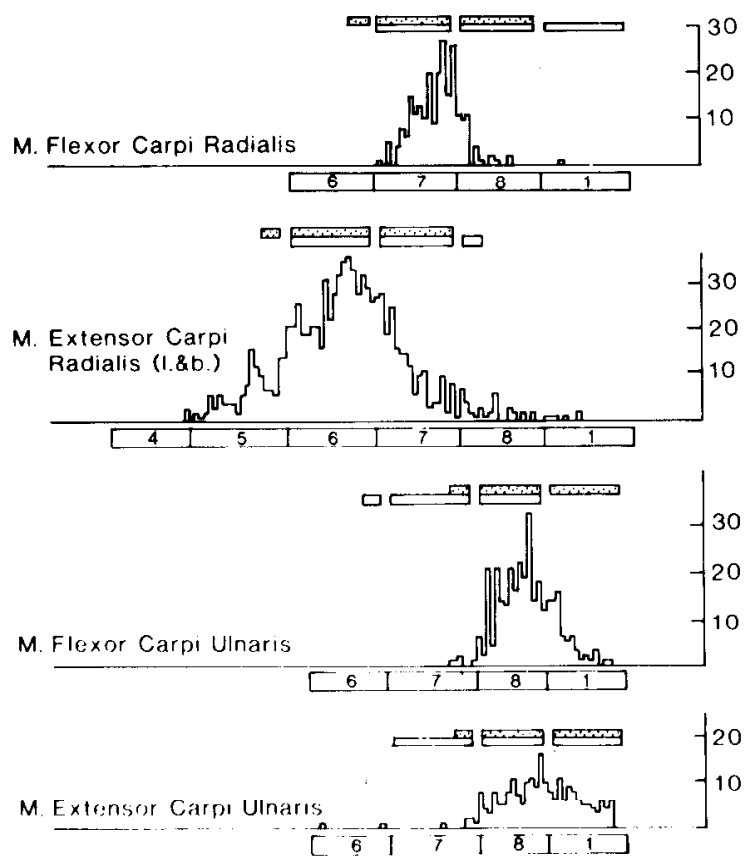

deeper planes of dissection. In order to minimize the spread of HRP to other muscles, the injections were made in the portions of exposed muscle around which barriers could be positioned. The amount of HRP injected relative to the sizes of the muscles was less than in other muscles studied and for this reason, not all of the motoneurons might have been labeled.

The biceps motoneurons were centered in $\mathrm{C} 5$ and $\mathrm{C} 6$ and extended into C7 and C8. The labeling of some motoneurons in caudal $\mathrm{C} 7$ and $\mathrm{C} 8$ was unexpected and may have resulted from the spread of HRP to the underlying brachialis or coracobrachialis muscles. The rostral

\section{FOREARM MUSCLES (Hand)}

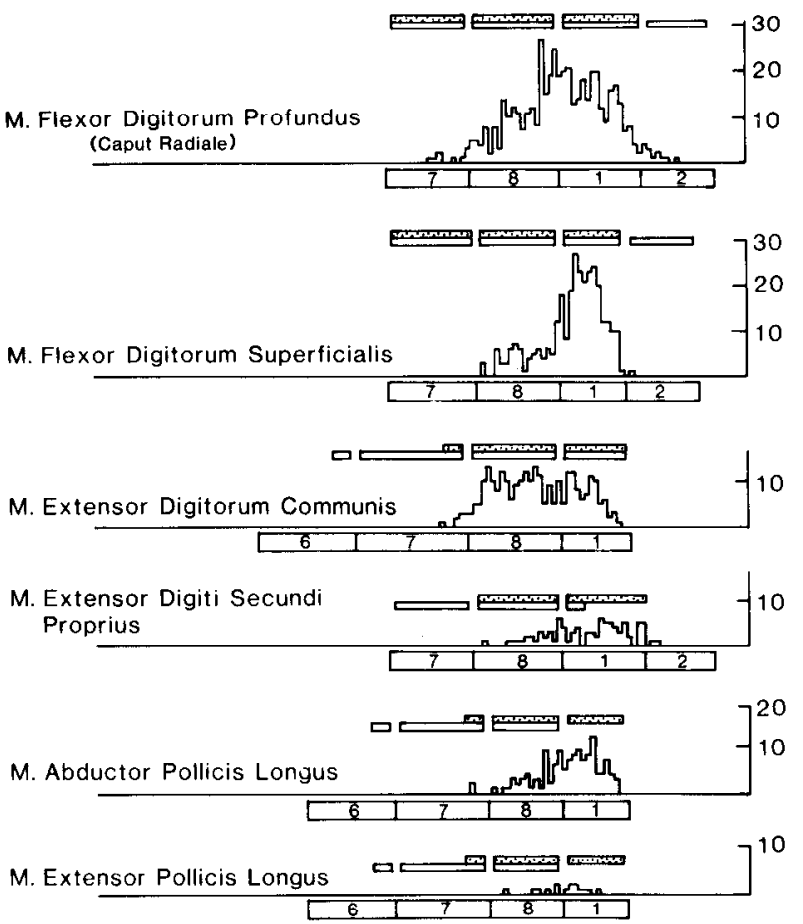

HAND MUSCLES

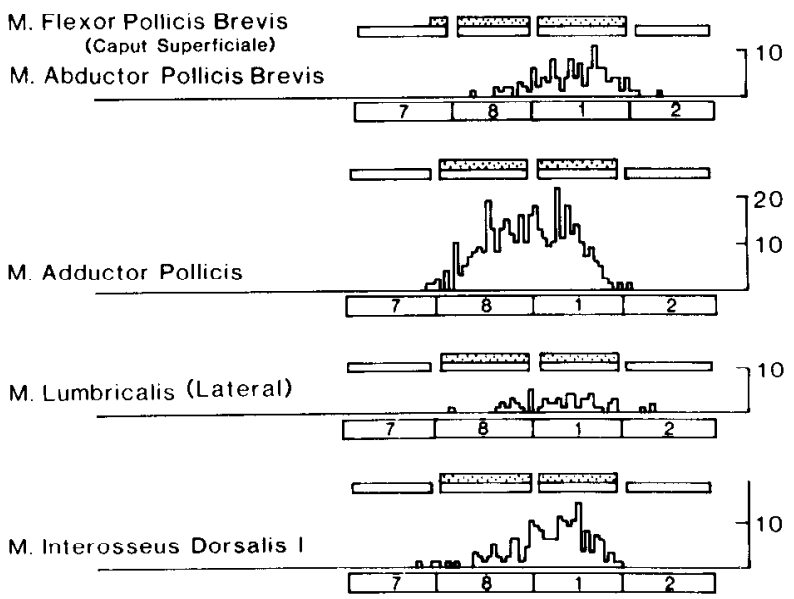

Figure 4. Segmental distribution of motoneurons innervating selected muscles of the macaque forelimb expressed as the number of labeled motoneurons per $250-\mu \mathrm{m}$ rostrocaudal distance. Sherrington's (1898) data have been entered for correlation. The stippled hars represent his physiological data and the open bars represent anatomical data. Sherrington did not study C5 anatomically. 


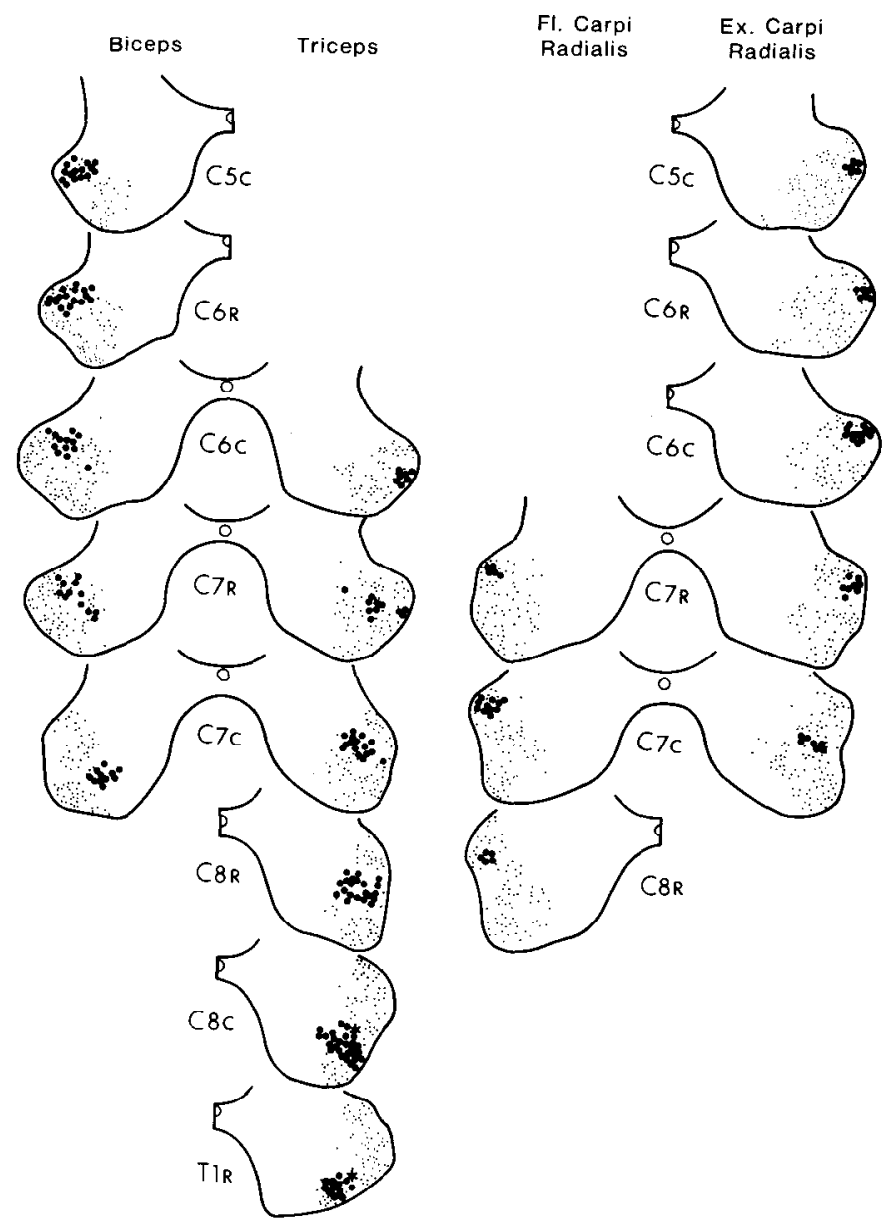

Figure 5. Location of HRP-labeled motoneurons (large dots) innervating the biceps and triceps brachii and flexor and extensor carpi radialis muscles. Small dots represent unlabeled motoneurons. Asterisks indicate the central position of the triceps motor column at $\mathrm{C} 7$ relative to the central canal. The injection data are as follows: Biceps, 150,000 units of HRP (546 mg) in $6.0 \mathrm{ml}, 1,051$ motoneurons ( $M$. fascicularis $79-1,4.2 \mathrm{~kg}$, right). Triceps, 150,000 units of HRP (546 mg) in $6.0 \mathrm{ml}, 1,271$ motoneurons ( $M$. fasicularis 79-1, left). Fl. Carpi Radialis, 62,000 units of HRP (216 mg) in $2.5 \mathrm{ml}, 235$ motoneurons ( $M$. mulatta $78-6,3.0 \mathrm{~kg}$, right). Ex. Carpi Radialis (longus and brevis), 87,500 units of HRP ( $303 \mathrm{mg}$ ) in $3.5 \mathrm{ml}, 890$ motoneurons ( $M$. mulatta 78-6, left).

end of the biceps motor column was located among the dorsolateral neurons of the anterior horn. In more caudal sections the labeled motor column became flanked by more lateral and dorsal motor groups which were unlabeled.

The triceps motor group was located in $\mathrm{C} 7, \mathrm{C} 8$, and $\mathrm{T} 1$, with minor numbers of cells extending into $\mathrm{C} 5, \mathrm{C} 6$, and T2. The rostral end of the group was located among the dorsolateral neurons of the anterior horn; in more caudal sections (caudal C8) the column shifted slightly medially.

Forearm muscles acting on the wrist. The four muscles studied were the flexor carpi radialis, flexor carpi ulnaris, extensor carpi radialis (longus and brevis), and extensor carpi ulnaris (Figs. 4 to 6 ).

Radial extensor motoneurons were labeled in $\mathrm{C} 5, \mathrm{C} 6$, and $\mathrm{C} 7$ and ulnar extensor motoneurons were labeled in
$\mathrm{C} 8$ and T1. The rostral ends of the labeled motor groups were found among the more dorsolateral cells of the dorsolateral nucleus. In more caudal sections the columns shifted slightly medially and ventrally.

The radial flexor motoneurons were in $\mathrm{C} 7$ and rostral $\mathrm{C} 8$ and the ulnar flexor motoneurons were in $\mathrm{C} 8$ and rostral $\mathrm{T} 1$. In $\mathrm{C} 7$ and rostral $\mathrm{C} 8$, the flexor columns overlapped. The rostral end of the column lay dorsomedial to the extensor columns; in C8 and rostral T1 the motor column shifted slightly ventromedially.

Forearm muscles acting on the hand. The six muscles studied were the digitorum superficialis, flexor digitorum profundus (radial head), extensor digitorum communis, extensor digiti secundi proprius, extensor pollicis longus, and abductor pollicis longus. Most of the labeled moto. neurons were located in C8 and T1 (Figs. 4, 6, and 7).

The flexor motor columns innervating finger flexors appeared to overlap topographically. The rostral ends were grouped in the dorsomedial part of the dorsolateral nucleus. In caudal sections the labeled motoneurons expanded into the medial and lateral parts of the dorsolateral nucleus and the labeled deep flexor column shifted slightly ventrally.

The extensor motor columns innervating the finger and thumb extensors also appeared to overlap topographically. The rostral motoneurons were in the lateral part

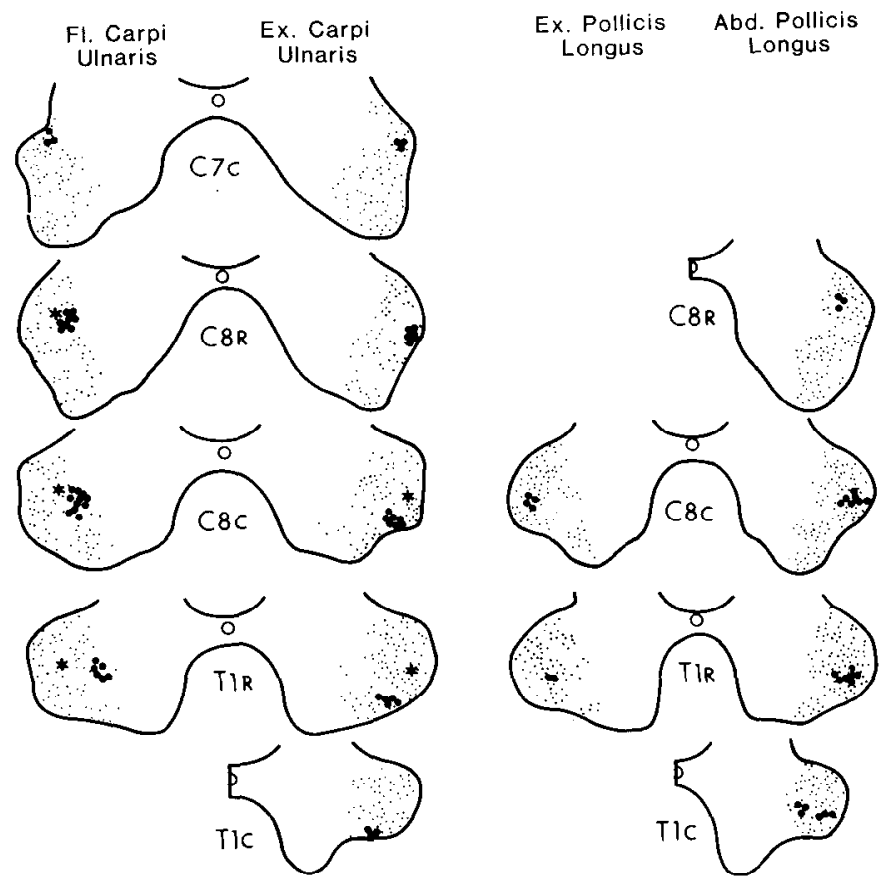

Figure 6. Location of motoneurons innervating the flexor and extensor carpi ulnaris and extensor and abductor pollicis longus muscles. Asterisks indicate positions of motor groups at caudal C7 relative to the central canal. The injection data are as follows: Fl. Carpi Ulnaris, 100,000 units of HRP (346 Ing) in $4.0 \mathrm{ml}, 314$ motoneurons (M. mulatta $78-5,3.0 \mathrm{~kg}$, right). Ex. Carpi Ulnaris, 50,000 units of HRP $(173 \mathrm{mg})$ in $2.0 \mathrm{ml}, 216$ motoneurons (M. mulatta 78-5, left). Ex Pollicis Longus, 5,000 units of HRP (18 mg) in $0.2 \mathrm{ml}, 14$ motoneurons (M. fascicularis $79-4,4.2 \mathrm{~kg}$, right). Abd. Pollicis Longus, 20,000 units of HRP (73 mg) in $0.8 \mathrm{ml}, 126$ motoneurons (M. fascicularis 79-4, left). 


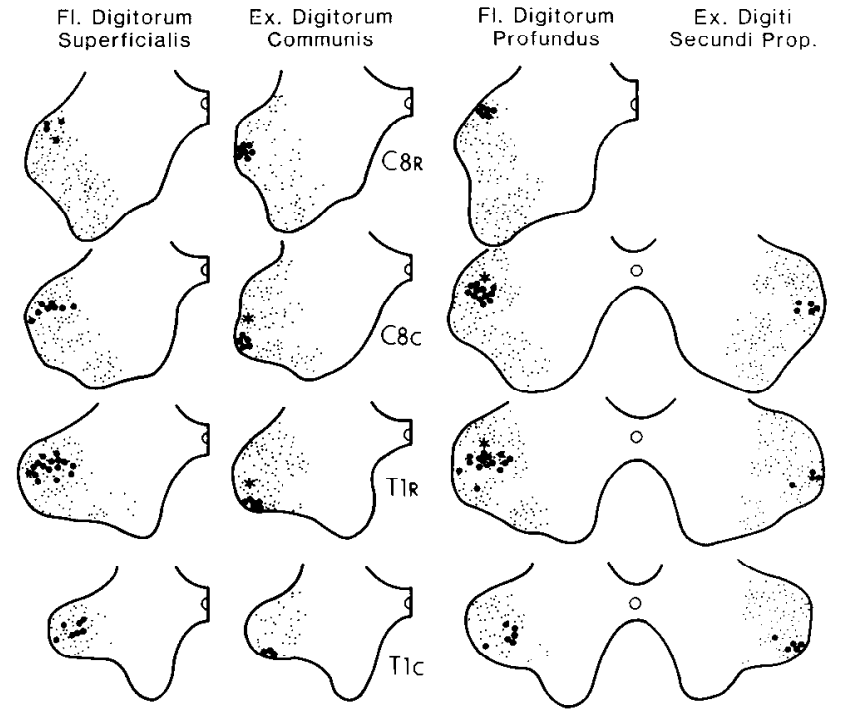

Figure 7. Location of motoneurons innervating the flexor digitorum profundus (radial head) and superficialis, extensor digitorum communis, and extensor digiti secundi proprius muscles. Asterisks indicate positions of motor groups at rostral C8 relative to the central canal. The injection data are as follows: $\mathrm{Fl}$. Digitorum Superficialis, 100,000 units of HRP (346 mg) in $4.0 \mathrm{ml}, 306$ motoneurons ( $M$. mulatta $78-7,3.0 \mathrm{~kg}$, right). Ex. Digitorum Communis, 50,000 units of HRP (173 mg) in $2.0 \mathrm{ml}$, 273 motoneurons (M. mulatta $78-3,4.0 \mathrm{~kg}$, right). Fl. Digitorum Profundus, 90,000 units of HRP (311 mg) in $3.6 \mathrm{ml}, 475$ motoneurons (M. mulatta 78-8, $3.1 \mathrm{~kg}$, right). Ex Digiti Secundi Prop., 10,000 units of HRP (35 mg) in $0.4 \mathrm{ml}, 87$ motoneurons (M. mulatta 78-8, left).

of the dorsolateral nucleus. Some of the motor groups shifted slightly ventrally in caudal sections.

Hand muscles. Five muscles which act on the thumb and index finger were studied (Figs. 4 and 8). These were the first dorsal interosseus, the abductor and flexor pollicis brevis, the lateral lumbrical, and the adductor pollicis muscles. Their motoneurons, when labeled, were scattered throughout the retrodorsolateral nuclear group in segments C8 and T1; some motoneurons were found in T2. Considerable topographical overlap of the motoneuron groups was found. The motoneuron columns innervating the abductor and flexor pollicis brevis muscles were the most clearly defined and were localized to the ventromedial aspect of the retrodorsolateral nucleus.

\section{Discussion}

Analysis of extensor digitorum communis motoneurons. The motor group of the extensor digitorum communis (EDC) numbered about 300 motoneurons and formed a rostrocaudal column in the caudal half of the cervical enlargement. The segmental distributions of labeled neurons in different experiments differed and presumably reflected the segmental variability of the brachial plexus observed by Sherrington (1898). Most of the variability in position of the EDC motoneurons occurred between $\mathrm{C} 8$ and T1 (Table I). Extension of the group into caudal $\mathrm{C} 7$ was minor (under $3 \%$ ) and variable. Moreover, when labeled EDC motoneurons were charted at $250-\mu \mathrm{m}$ intervals, the rostrocaudal position of the motor group appeared constant (Fig. 2). This suggested that the segmental and topographical positions of the bulk of the motor groups studied in individual experiments were representative of the muscle and that motoneuron groups could be compared in composite reconstructions.

The relative numbers of $\alpha$ and $\gamma$ motoneurons were difficult to assess. The smallest labeled neurons (cat, 16 to $25 \mu \mathrm{m}$; monkey, 20 to $30 \mu \mathrm{m}$ ) were found along the entire length of the motoneuron column and did not have any special distribution within the motor group. Burke et al. (1977) found a bimodal distribution of motoneurons in the medial gastrocnemius motor pool and concluded that motoneurons under $37.5 \mu \mathrm{m}$ were probably $\gamma$ motoneurons; these comprised $25 \%$ of the motoneurons labeled. We found a similar bimodal distribution when neuron size was measured in the rostrocaudal axis (Fig. 3). If EDC motoneurons below $35 \mu \mathrm{m}$ were considered $\gamma$ neurons, $50 \%$ of the cat and $14 \%$ of the macaque motor group would represent $\gamma$ innervation.

The question of $\alpha$ and $\gamma$ innervation was complicated by the fact that when axon analysis was compared with motoneuron analysis (Fig. 3), the data differed significantly. We measured axon diameters in a deafferented motor nerve and found a bimodal distribution of motor axons similar to that found by others (Eccles and Sherrington, 1930; Boyd and Davey, 1968). Although the data might be influenced by branching axons, our percentage of smaller axons was $46 \%$. Boyd and Davey (1968) subdivided the $\gamma$ group of axons into thickly and thinly myelinated fibers. A similar variation in myelin thickness

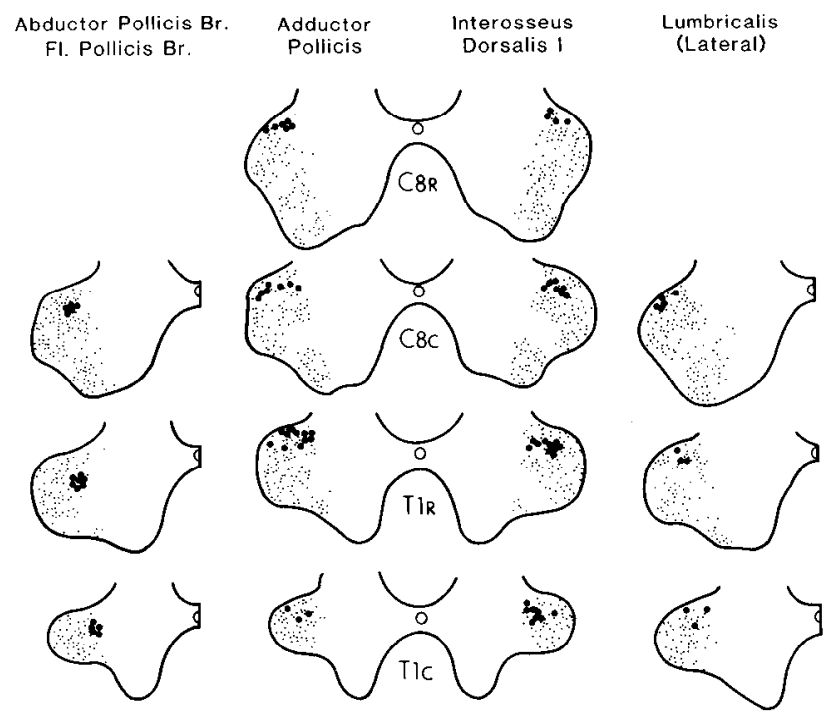

Figure 8. Topographical distribution of motoneurons innervating selected hand muscles. The injection data are as follows: Abductor and Fl. Pollicis Br., 17,500 units of HRP (61 mg) in $0.7 \mathrm{ml}, 115$ motoneurons ( $M$. mulatta $78-10,3.9 \mathrm{~kg}$, right). Adductor Pollicis, 15,000 units of HRP (53 mg) in $0.38 \mathrm{ml}, 370$ motoneurons ( $M$. mulatta $78-11,3.3 \mathrm{~kg}$, right). Interosseus Dorsalis $I, 10,000$ units of HRP (35 mg) in $0.25 \mathrm{ml}, 172$ motoneurons ( $M$. mulatta 78-11, left). Lumbricalis (Lateral), 10,000 units of HRP ( $35 \mathrm{mg}$ ) in $0.25 \mathrm{ml}, 57$ motoneurons (M. mulatta $78-9,3.1 \mathrm{~kg}$, right). Contamination was suspected in the adductor pollicis and interosseus dorsalis I injections. 
was observed around the smaller fibers (under $9 \mu \mathrm{m}$ ) in the present study.

Which analysis should be used to quantitate the $\alpha$ and $\gamma$ motoneuron pools? If axons under $9 \mu \mathrm{m}$ represent $\gamma$ innervation $(46 \%)$, a similar number of small motoneurons would be anticipated in the anterior horn. However, only $14 \%$ of the labeled motoneurons are under $35 \mu \mathrm{m}$. The quantitative control data and the ability to label small motoneurons under $35 \mu \mathrm{m}$ after injections in the cat EDC argue against the possibility of large numbers of small motoneurons being unlabeled. One explanation of the discrepancy is that some small $\alpha$ motoneurons may have primary or branching axons under $9 \mu \mathrm{m}$ in diameter at the level measured.

Segmental organization. Of the four largest segments (C6, C7, C8, and T1) forming the brachial plexus, the motoneurons controlling hand movement were located primarily in segments $\mathrm{C} 8$ and $\mathrm{T} 1$. This included motoneurons innervating both intrinsic hand muscles and extrinsic forearm muscles acting on the hand.

The innervation of muscles acting on the wrist extended from $\mathrm{C} 5$ to $\mathrm{T} 1$. The radial extensor motor group was in $\mathrm{C} 5, \mathrm{C} 6$, and $\mathrm{C} 7$ and the radial flexor motor group was primarily in $\mathrm{C}$. The ulnar flexor and extensor motor groups lay in $\mathrm{C} 8$ and $\mathrm{T} 1$.

The segmental innervation of the muscles studied was compared to Shcrrington's (1898) electrophysiological data (Fig. 4). In order to compensate for current spread, Sherrington (1898) stimulated isolated ventral nerve roots after adjacent nerve roots had been sectioned and allowed to degenerate. Where only a "few" muscle fibers were observed to contract, the bars in Figure 4 have been truncated; this lesser innervation occurred at rostral or caudal ends of the motor group and correlated well with the decreasing numbers of HRP-labeled motoneurons.

The only muscle studied in which the data differed from those of Sherrington (1898) was the biceps brachii. Although most of the labeled motoneurons were at C5 and C6, in agreement with Sherrington (1898), some HRP-labeled motoneurons were found in $\mathrm{C} 7$ and $\mathrm{C} 8$. The dissection of the biceps from the underlying brachialis and coracobrachialis muscles may not have been sufficient to prevent spread of some HRP to these muscles, which Sherrington (1898) had found to extend their caudal innervation into $\mathrm{C} 7$ (coracobrachialis into C8).

Sherrington (1898) also studied the segmental innervation of the cervical cord with companion anatomical experiments in which single ventral roots were sectioned and motor nerves were later examined for Wallerian degeneration. Sherrington (1898) thought that the anatomical method was more sensitive in demonstrating a muscle's segmental innervation. At the ends of the motor column, Sherrington (1898) found that degenerating axons were usually present when the physiological response was weak and that lesser numbers of degenerating axons were present when no physiological response was seen. Quantitative estimates of degenerating axons greater than "several" were not reported. Since axonal branching was probably present at the level of motor nerve dissection, the innervation from a given cervical segment, particularly at rostral and caudal ends of the motoneuron column, was probably overestimated.

From a quantitative standpoint the best correlation of segmental innervation occurred between the HRP data and Sherrington's (1898) electrophysiological data. At the rostral and caudal segments of the motoneuron column, minimal physiological responses correlated well with reduced numbers of HRP-labeled motoneurons.

Topographical organization. Two gencral observations concerning topographical organization were made. First, the rostral ends of the motor columns were usually among the dorsal motoneurons of the anterior horn. In more caudal sections, the motor column lost its relative position along the dorsolateral border of the anterior horn gray matter as additional motor columns appeared in the dorsolateral and retrodorsolateral regions. Some motor columns did undergo a real ventral shift relative to the central canal with the introduction of major groups of more dorsally positioned motoneurons.

The motor columns of the biceps and extensor carpi radialis muscles maintained their position from C5 through rostral $\mathrm{C} 7$. At caudal $\mathrm{C} 7$ these columns shifted ventrally and medially as forearm motor columns appeared. The forearm motor columns, in turn, shifted slightly ventrally as the hand motor columns appeared in caudal $\mathrm{C} 8$.

The second observation was that motor columns innervating forearm muscles with similar actions on the hand appeared to overlap in the anterior horn. Wrist extensor motoneurons were generally positioned ventral and lateral to wrist flexor motoneurons. This relationship was best seen with the motor columns of the ulnar flexor and extensor muscles which were present at similar segments. The ventrolateral position of the extensor motor column was maintained during the ventral displacement of the caudal ends of the motor groups. A slightly different topographical pattern occurred with the forearm finger flexor and extensors. Although the rostral extensor motoneurons were ventral and lateral to flexor motoneurons, in the caudal sections extensor motoneurons lay ventral to flexor motoneurons as the flexor motor groups expanded laterally in the anterior horn.

The topographical organization can be appreciated in summary reconstructions (Fig. 9). At rostral C7, four of the motor groups studied are present. Motoneurons innervating forearm muscles were dorsal to those innervating arm muscles. The position of the biceps group was unchanged from $\mathrm{C} 5$, where its neurons were among the most dorsal and lateral motoneurons. In rostral $\mathrm{C} 7$, the motor columns of the wrist muscles appeared dorsally and the motor column of the triceps appeared laterally.

At caudal C8, the triceps motor group had shifted slightly medially. Adjacent dorsally were the motoneurons innervating ulnar wrist muscles. Motor groups controlling finger movement comprised the remainder of the dorsolateral nucleus with the flexor motoneurons positioned dorsal to those which extended the thumb and digits. The most dorsal neurons were those innervating hand muscles. Although motoneurons of the thumb flexors were medial, no other clear pattern of organization was noted.

Physiologically, the organization of dendrites may be more important than the sites of neuronal somata, since the dendritic membrane represents the bulk of the synaptic surface of the motoneuron. Although motoneurons have radially directed dendrites (Romanes, 1964; Schei- 


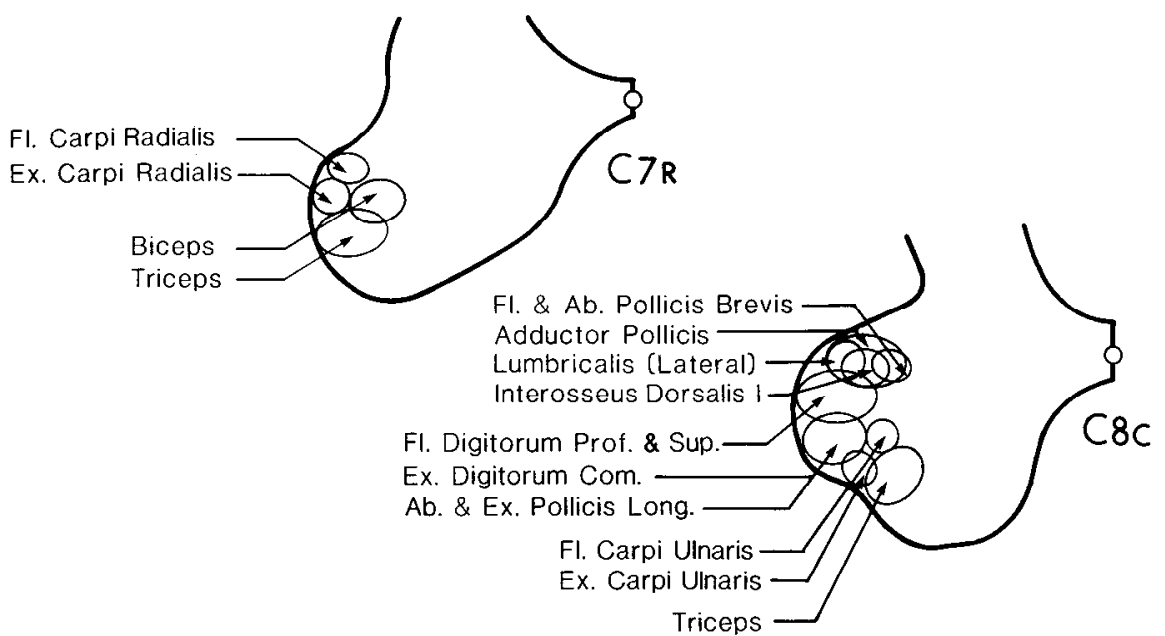

Figure 9. Topographical distribution of motor columns at rostral $\mathrm{C} 7$ and caudal $\mathrm{C} 8$ segments. The data are schematic principles of organization of the anterior horn.

bel and Scheibel, 1973; Light and Metz, 1978), most of the dendritic tree is oriented parallel to the long axis of the spinal cord and is associated with the motor groups (Sterling and Kuypers, 1967; Scheibel and Scheibel, 1970; Dekker et al., 1973). The combined data suggest that the predominant organization of dendrites and motoneurons which innervate an individual forearm muscle occurs as a rostrocaudal columnar zone which is topographically positioned in the anterior horn among motor groups of similar function.

\section{References}

Boyd, I. A., and M. R. Davey (1968) Composition of Peripheral Nerves, E. \& S. Livingstone Ltd, Edinburgh and London.

Buchthal, F., and H. Schmalbruch (1980) Motor unit of mammalian muscle. Physiol. Rev. 60: 90-142.

Burke, R. E., P. L. Strick, K. Kanda, C. C. Kim, and B. Walmsley (1977) Anatomy of medial gastrocnemius and soleus motor nuclei in cat spinal cord. J. Neurophysiol. 40: 667680 .

Dekker, J. J., D. G. Lawrence, and H. G. J. M. Kuypers (1973) The location of longitudinally running dendrites in the ventral horn of the cat spinal cord. Brain Res. 51: 319-325.

Eccles, J. C., and C. S. Sherrington (1930) Numbers and contraction-values of individual motor-units examined in some muscles of the limb. Proc. R. Soc. Lond. Biol. 106: 326-257.

Eccles, R. M., C. G. Phillips, and W. Chien-Ping (1968) Motor innervation, motor unit organization and afferent innervation of m. extensor digitorum communis of the baboon's forearm. J. Physiol. (Lond.) 198: 179-192.

Hartman, C. G., and W. L. Strauss, Jr. (1933) The Anatomy of the Rhesus Monkey, Hafner Publishing Co., New York.

Landmesser, L. (1978) The distribution of motoneurones supplying chick hind limb muscles. J. Physiol. (Lond.) 284: 371389.
Light, A. R., and C. B. Metz (1978) The morphology of the spinal cord efferent and afferent neurons contributing to the ventral roots of the cat. J. Comp. Neurol. 179: 501-516.

Matsuda, K., M. Uemura, M. Kume, R. Matshushima, and N. Mizuno (1978) Topographical representation of masticatory muscles in the motor trigeminal nucleus in the rabbit: A HRP study. Neurosci. Lett. 8: 1-4.

Mesulam, M. (1976) The blue reaction product in horseradish peroxidase neurohistochemistry: Incubation parameters and visibility. J. Histochem. Cytochem. 24: 1273-1280.

Reed, A. F. (1940) The nuclear masses in the cervical spinal cord of Macaca mulatta. J. Comp. Neurol. 72: 187-206.

Richmond, F. J. R., D. A. Scott, and V. C. Abrahams (1978) Distribution of motoneurones to the neck muscles, biventor cervicis, splenius and complexus in the cat. J. Cormp. Neurol. 181: $451-464$.

Romanes, G. J. (1951) The motor cell columns of the lumbosacral spinal cord of the cat. J. Comp. Neurol. 94: 313-364.

Romanes, G. J. (1964) Motor pools of the spinal cord. Prog. Brain Res. 11: 93-119.

Sato, M., N. Mizuno, and A. Konishi (1978) Localization of motoneurons innervating perineal muscles: A HRP study in cat. Brain Res. 140: 149-154.

Scheibel, M. E., and A. B. Scheibel (1970) Organization of spinal motoneuron dendrites in bundles. Exp. Neurol. 28: 106-112.

Scheibel, M. E., and A. B. Scheibel (1973) Dendrite bundles in the ventral commissure of cat spinal cord. Exp. Neurol. 39: $482-488$.

Sherrington, C. S. (1898) Experiments in examination of the peripheral distribution of the fibres of the posterior roots of some spinal nerves. Philos. Trans. R. Soc. Lond. Biol. 190B: $45-186$.

Sprague, J. M. (1948) A study of motor cell localization in the spinal cord of the rhesus monkey. Am. J. Anat. 82: 1-26.

Sterling, P., and H. G. J. M. Kuypers (1967) Anatomical organization of the brachial spinal cord of the cat. II. The motoneuron plexus. Brain Res. 4: 16-32. 